\title{
Irrigation network extraction in arid regions with using worldview-2 satellite data
}

\author{
Shamshod Akmalov ${ }^{*}$, Luqmon Samiev, Tursunoy Apakhodjaeva, Dinislom Atakulov, and \\ Sarvar Melikuziyev \\ Tashkent Institute of Irrigation and Agricultural Mechanization Engineers, Tashkent, Uzbekistan
}

\begin{abstract}
After the 2000s, the launch of very high-resolution satellites provided great water and irrigation network management personnel opportunities. Now, the water management staff have the opportunity to study and monitor water supply systems and exploitation conditions of irrigation systems remotely via satellite imagery. By using those satellite images, specialists can search for water bodies, detect defected place of irrigation systems, and monitor their technical condition. Another advantage of satellite imagery is that they capture large areas of the Earth, keeping water systems under control in large areas. Therefore, the use of very high-resolution images has greatly developed in the water branch since the 2000s. The creation of different water extraction methods, models, indexes, and using different layers in the analysis for different regions using different satellites with very high resolution is developed. These indexes and layers are so numerous that they are now over 100. The user has difficulty getting any of them in the analyzes. Therefore, in this article, we have studied more than 50 water extraction methods, which gave positive and accurate results in an arid region. From those 50 methods, separated 10 the most effective methods and tested with WorldView-2 image analysis in the arid region and the water-rich region of Syrdarya region. According to the results of the analysis recommend the highest accuracy method for arid areas. Results show that water extraction using NIR2 layer of the WorldView-2 satellite images is the most accurate method than other methods. The accuracy of the results was $94 \%$. The analysis found the irrigation systems filled with sand and vegetation.
\end{abstract}

\section{Introduction}

Remote Sensing (RS) investigated many methods for extraction water objects. Most of them gave accurate results in different fields and different satellites. Below we use most resultables from them for the arid region and WorldView-2 (WV-2) images. The most useful band to classify this class is the NDWI (Normalized Difference of Water Index). NDWI is the index for calculating water objects, which was first described in McFeeters' scientific work in 1996. He created the following NDWI formula for calculating in Landsat images [15]:

\footnotetext{
*Corresponding author: shamshodbekjon@mail.ru
} 


$$
\mathrm{NDWI}_{\mathrm{M}}=(\mathrm{G}-\mathrm{NIR}) /(\mathrm{G}+\mathrm{NIR})
$$

There: $\mathrm{G}$ is green band of satellite images, NIR-Near infrared band of satellite images

It is possible to create it for all satellite images with the two layers mentioned above. NDWI degree changes from -1 to 1 . A positive degree means the existence of a water basin in the researching area; a negative degree means its opposite.

$\mathrm{Xu}$ expresses the NDWI counting formula in Landsat image in the following way [22]:

$$
\mathrm{NDWID}_{\mathrm{X}}=(\mathrm{NIR}-\mathrm{SWIR}) /(\mathrm{NIR}+\mathrm{SWIR})
$$

There: SWIR is Short-wave infrared band of satellite images.

Ramoelo, Cho, and $\mathrm{Xu}$ used this formula to determine biomass by Landsat images in the dry season and find dead biomass. Short-wave infrared (SWIR) from Landsat 8 is the most important specter in determining water stress in plants. At this specter of light, cellulose and nitrogen produced by plants are absorbed in a high amount, and the reflectance is very high. According to Ramoelo and Cho, there is a connection between NDWI and the dead plants. It explains why the dead areas join to water bodies in determining the water objects from Landsat 8 images.

$\mathrm{Xu}$ suggested a modified NDWI to increase the sensitivity of NDWI in Landsat image layers; here, he used band MIR (middle infrared) instead of band NIR [22]:

$$
\mathrm{NDWI}_{\mathrm{HX}}=(\mathrm{G}-\mathrm{MIR}) /(\mathrm{G}+\mathrm{MIR})
$$

There: MIR is middle infrared band of satellite images

Dao and Liou made some changes to the formula while mapping the flooded areas of Cambodia by OBIA classifying the Landsat 8 images. The correlation coefficient of the results was $90-93 \%$, but clouds in some areas obstructed the clarity of results [Dao and Liou, 2015]:

$$
\mathrm{NDWI}_{\mathrm{D}}=(\mathrm{G}-\mathrm{SWIR}) /(\mathrm{G}+\mathrm{SWIR})
$$

These changes in formula gave better results than determining NDWI for Landsat images as suggested by McFeeters [22]. But we cannot use this formula for all the satellite images as some of them do not have bands of MIR and SWIR.

Yang and Smith emphasize that the $\mathrm{NDWI}_{\mathrm{M}}$ formula shows the absorbency of the NIR wavelength into soil and plants and that this formula gives a good result in common soil plant areas. If the research area is covered with snow and glaciers, the clarity of this formula decreases; because the snow and glaciers have particular features. This feature decreases the reflection of water. When it is difficult to determine the water objects, it is necessary to use the sensitive feature of the red image. With this, we can capture the reflective feature of water [1-4].

Bruce Pengra researched Landsat 30m continuous field-tree cover data creation and analysed it in very high-resolution data for South America. The following steps have been done in the research. The land cover database was created by using long-term data of Landsat, and its clarity was checked by WV-2 very high-resolution data. In scientific works, the NDWI layer was created by using Landsat and WV-2 images to determine water objects. To create this layer, they used McFeeter's (1) formula created in 1996 for Landsat images and (11) formulas created by Jawak and Luis for WV-2 images. But, errors of water objects extraction were not taken into account as the main object was a tree-covered area in the statistical analysis of the results. $\mathrm{R} 2=0.82$ for the tree-covered area [5-7]. It remains unknown how many mistakes there are in determining water bodies. 
The most efficient formula among the previously mentioned calculating formulas of NDWI is NDWI McFeeters' formula, used widely in Landsat image analyses. Besides, all layers used by McFeeters exist in the Landsat satellite, so we shall use them to classify water objects as well. And for VW images, the following calculating indices of NDWI have been created:

According to the results of the analysis of the literature, we found the following NDWI formulas using WV-2 images. In WV-2 images analysis of much scientific research, the NDWI index was used, which is developed by McFeeters, created from NIR1 and Green bands [15]:

$$
\mathrm{NDWI}_{\mathrm{M}}=(\mathrm{G}-\mathrm{NIR}) /(\mathrm{G}+\mathrm{NIR})
$$

Belgiu used the formula counting NDWI that McFeeters suggested in distinguishing water objects from urban land using classification with WV-2 [5]. Marco Gianinetto used $\mathrm{NDWI}_{\mathrm{M}}$ (1) calculating formula for a complex classifying small area in Venice province, Italy, by QuickBird multispectral image and got $85 \%$ accuracy [9].

Wolf suggested the following formula in counting NDWI index from WV-2 images, taking advantage of the existence of the coastal band and NIR2 band that is more sensitive than NIR1 band in WV-2 images [20]:

$$
\mathrm{NDWI}_{\mathrm{W}}=(\mathrm{C}-\mathrm{NIR} 2) /(\mathrm{C}+\mathrm{NIR} 2)
$$

There: $\mathrm{C}$ is coastal band of satellite images, NIR2 is 2nd near-infrared band of satellite images.

Water objects are clear in his results. In addition, his formula succeeded in some other research as well. Ronczyk used $\mathrm{NDWI}_{\mathrm{W}}$ formula in water object classification for urban land cover extraction for Szekesfehervar city in Hungary [19]. Plat analysed, in integration, LIDAR and very high-resolution images in predicting and studying the danger of natural fair in inhabitant areas close to forest areas in the western parts of Boulder city, Colorado State, USA. He used WV-2 images in his research. He had calculated NDWI by Wolf's formula and used it in determining the forest areas and classification. In these analyses, errors of omission are $16 \%$, errors of commission are $9 \%$ in classification [16].

Maglione, Parente, and Vallario used different indices and WV-2 high-resolution images for classifying the Campania region in Italy. He used the $\mathrm{NDWI}_{\mathrm{W}}$ - formula suggested by Wolf for calculating NDWI, and when this calculating algorithm was determined by the Maximum Likelihood Method, he emphasized that it gives quite better results than calculating NDWI algorithm [14]. Chen reckons that using the following formula for calculating NDWI while OBIA classifying the WV-2 images will increase the clarity of results [3]:

$$
\mathrm{NDWI}_{\mathrm{Ch}}=(\mathrm{G}-\mathrm{NIR} 2) /(\mathrm{G}+\mathrm{NIR} 2)
$$

He explains the formula as follows: WV-2 satellite NIR2 sensor has low brightness in water and high brightness in plants. Furthermore, one can distinguish between water and plant by calculating the $\mathrm{NDWI}_{\mathrm{Ch}}$ with the formula [3].Huang suggested using pixel and object, namely, double analyse tools as well as choosing the most appropriate index in determining water objects in VHR images, and proved that it is possible to get a better result in this way [10]. Baiocchi used $\mathrm{NDWI}_{\mathrm{Ch}}$ formulas indicating the limit of sea and Italian coasts [4]. Alsubaie (2012) used $\mathrm{NDWI}_{\mathrm{Ch}}$ formula to analyze the Bathymetry and $\mathrm{RS}$ VHR images in integration and study the depth of a water basin for San Francisco Bay; in his works, he mentioned that band NIR2 of WV-2 images is better than band NIR1 [2]. 
Most of the scientists suggest using WV-2 images in determining and classifying water objects. It can determine very small water objects as it has a very high resolution. In addition, as it has many spectral bands, it is easy to calculate and create different NDWI indices, choose the most appropriate band combination and make band-combinations in determining water basins. Afterward, many scientists suggested NDWI calculating formulas in different conditions and tested them in research.

In spectral ratio based on land cover mapping of Antarctic analyses, Jawak managed to classify the World View images by indices. Here the most used indices are NDWI and NDVI. This was based on Gao's theory, who had created many formulas for calculating the NDWI index, which is the main index in classifying the stagnant water basins. Based on this theory, he discovered some new formulas for finding NDWI for WV-2 images. The formulas are the following [11]:

$$
\begin{aligned}
& \mathrm{NDWI}_{\mathrm{J} 1}=(\mathrm{C}-\mathrm{NIR} 1) /(\mathrm{C}+\mathrm{NIR} 1) \\
& \mathrm{NDWI}_{\mathrm{J}}=(\mathrm{B}-\mathrm{NIR} 1) /(\mathrm{B}+\mathrm{NIR} 1) \\
& \mathrm{NDWI}_{\mathrm{J} 3}=(\mathrm{B}-\mathrm{NIR} 2) /(\mathrm{B}+\mathrm{NIR} 2)
\end{aligned}
$$

There: $\mathrm{B}$ is blue band of satellite images

Combinations made with coastal, namely with $\mathrm{NDWI}_{\mathrm{J} 1}$ and $\mathrm{NDWI}_{\mathrm{Wolf}}$ algorithms, gave better results in analyses based on the algorithms mentioned above. By these formulas, 97 stagnant water basins from 109 water objects have been determined successfully. Sensitivity of these indexes for water objects with a size of more than 130-200 m2. Because the surface of water objects is smaller than the surface covered with ice, they are counted as a classification of snow coverings. NDWI error of inclusion changes from 0.7 to $2.21 \%$ [12].

Khin had used the formula, determining NDWI in high-resolution images by Coastal and Blue bands that Jawak suggested, in urban drainage system modelling for San Clement city, California state [12]. Jawak and Luis (2015) invented a semi-automatic approach based on a new system of calculating NDWI for extracting melted water bodies in the Antarctic coastal oases area using high-resolution WV-2 data [11]. Khin used the NDWI calculating $\mathrm{NDWI}_{\mathrm{J} 2}$ - formula in classifying basins in inhabitant areas. The overall accuracy was equal to $72.03 \%$ in this research. In addition, it is necessary to emphasize that the analysing program was ERDAS IMAGINE 2013 RS in this research because this analysing program is a pixel-based program. It is assumed that it could decrease the indices of accuracy [12]. We will choose one of the NDWI formulas created for WV-2 images, which had been tested in an areal climate similar to the area we are studying, choose all indices, and test efficiency in our analysis.

\section{Materials and Methods}

Water bodies and irrigation sets. Using the formulas mentioned above for NDWI calculation in WV-2 image analysis in different conditions has given positive results. We used "Water object Classification with WV-2 image analysis" from all these formulas, and we evaluated the effectiveness of this formula (Table 1). The following formulas have been used:

$$
\begin{aligned}
& \mathrm{NDWI}_{\mathrm{M}}=(\mathrm{G}-\mathrm{NIR} 1) /(\mathrm{G}+\mathrm{NIR} 1)(1) \\
& \mathrm{NDWI}_{\mathrm{W}}=(\mathrm{C}-\mathrm{NIR} 2) /(\mathrm{C}+\mathrm{NIR} 2)(2) \\
& \mathrm{NDWI}_{\mathrm{Ch}}=(\mathrm{G}-\mathrm{NIR} 2) /(\mathrm{G}+\mathrm{NIR} 2)(3) \\
& \mathrm{NDWI}_{\mathrm{J} 1}=(\mathrm{C}-\mathrm{NIR} 1) /(\mathrm{C}+\mathrm{NIR} 1)(4)
\end{aligned}
$$




$$
\begin{aligned}
& \mathrm{NDWI}_{\mathrm{J} 2}=(\mathrm{B}-\mathrm{NIR} 1) /(\mathrm{B}+\mathrm{NIR} 1)(5) \\
& \mathrm{NDWI}_{\mathrm{J} 3}=(\mathrm{B}-\mathrm{NIR} 2) /(\mathrm{B}+\mathrm{NIR} 2)(6)
\end{aligned}
$$

Besides, we used different bands of images for water extraction (Table 1).

Table 1. Classification value of water objects for WV-2 data

\begin{tabular}{|c|c|c|c|c|c|c|c|}
\hline \multirow{2}{*}{$\begin{array}{c}\text { Satellite } \\
\text { name }\end{array}$} & \multirow{2}{*}{$\begin{array}{c}\text { Image } \\
\text { taken date }\end{array}$} & \multicolumn{4}{|c|}{ IF } & THEN & ELSE \\
\cline { 3 - 5 } & & NIR & NIR2 & Pan & RedEdge & & \\
\hline $\begin{array}{c}\text { WV2 (river } \\
\text { area) }\end{array}$ & $21 / 07 / 2011$ & $<=260$ & $<=430$ & $<=278$ & $<=360$ & $\begin{array}{c}\text { Water } \\
\text { bodies and } \\
\text { irrigation } \\
\text { sets }\end{array}$ & $\begin{array}{c}\text { Unclassi } \\
\text { fied }\end{array}$ \\
\hline $\begin{array}{c}\text { WV2 } \\
\text { (disert area) }\end{array}$ & $\begin{array}{c}12 / 09 / 201 \\
2\end{array}$ & $<=440$ & $<=420$ & $<=237$ & $<=420$ & \\
\hline
\end{tabular}

\begin{tabular}{|c|c|c|c|c|c|c|c|c|}
\hline \multirow{2}{*}{ 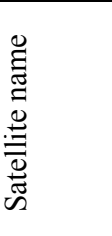 } & \multirow{2}{*}{ 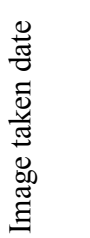 } & \multicolumn{5}{|c|}{ IF } & \multirow[b]{2}{*}{ 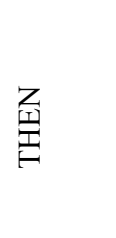 } & \multirow[b]{2}{*}{$\begin{array}{l}\text { 竞 } \\
\text { 至 }\end{array}$} \\
\hline & &  & 穴 & $\sum_{z}^{3}$ & 之 & $\frac{m}{2}$ & & \\
\hline $\begin{array}{l}\text { WV2 } \\
\text { (river } \\
\text { area) }\end{array}$ & $\begin{array}{l}21 / 07 \\
/ 2011\end{array}$ & $\begin{array}{c}<= \\
292\end{array}$ & $\begin{array}{c}<= \\
0.09\end{array}$ & $>=0$ & $>=0$ & $>=-0.1$ & \multirow{5}{*}{$\begin{array}{c}\text { Water } \\
\text { bodies } \\
\text { and } \\
\text { irrigatio } \\
\text { n sets }\end{array}$} & \multirow[t]{5}{*}{$\begin{array}{c}\text { Unclass } \\
\text { ified }\end{array}$} \\
\hline $\begin{array}{c}\text { WV2 } \\
\text { (disert } \\
\text { area) }\end{array}$ & $\begin{array}{l}12 / 09 \\
/ 2012\end{array}$ & $\begin{array}{c}<= \\
325\end{array}$ & $\begin{array}{c}<= \\
0.18\end{array}$ & $>=-0.1$ & $>=-0.05$ & $>=-0.18$ & & \\
\hline & & \multicolumn{2}{|c|}{$\mathrm{NDWI}_{\mathrm{J} 1}$} & $\mathrm{NDWI}_{\mathrm{J} 2}$ & \multicolumn{2}{|c|}{$\mathrm{NDWI}_{\mathrm{M}}$} & & \\
\hline $\begin{array}{l}\text { WV-2 } \\
\text { (river } \\
\text { area) }\end{array}$ & $\begin{array}{l}21 / 07 \\
/ 2011\end{array}$ & \multicolumn{2}{|c|}{$>=0.13$} & $>=0$ & \multicolumn{2}{|c|}{$>=0.1$} & & \\
\hline $\begin{array}{c}\text { WV2 } \\
\text { (disert } \\
\text { area) }\end{array}$ & $\begin{array}{l}12 / 09 \\
/ 2012\end{array}$ & \multicolumn{2}{|c|}{$>=0.12$} & $>=0.2$ & \multicolumn{2}{|c|}{$>=-0.06$} & & \\
\hline
\end{tabular}

Table 2. Water classification according to the different indices

As a result of the review of the analysis results, it had become clear that shadow joined the water objects. The spectral feature of the shadow is similar to that of water in all layers. And the formula calculating the shadow could not ease this problem. Lots of research was done to solve this problem by science. For example, in many research works, we can see that shadow joined water objects while determining them. But, several methods have already been created and experienced separating them from water objects in VHR images. In this analysis, an additional shadow, asphalt way, and urban areas are seen to water objects. That is why it is necessary to combine them in a special class. So, the shadow had been detached following its area. The smallest objects are the shadow.

The accuracy of results had been tested by classification accuracy.

In this analysis, images were used which were taken from two types of objects. These are the images of areas beyond the river of this region (Beshbulak village) and the desert area (Yangiobod village) in the region's center. These areas differ by their natural conditions, type of agriculture, and environment. The coastal area of the river is occupied with rice planting. This area is full of water plants and mostly consists of fenny areas. Plants are fully provided with water. The Desert area is primarily used for planting cotton, wheat, and vegetables. Good vegetation depends on a good supply of water. The aim was to 
identify the water resources of these two objects and choose an optimal method and testing eCognition opportunities. Regarding this issue, we organized a scientific expedition, which analysed these two territories and made up a map of water branches and water objects of these regions. Those water objects were created by GPS, and we measured their width. According to these investigations, the map of water sets and water objects on GIS has been established (Figures 1 and 2).

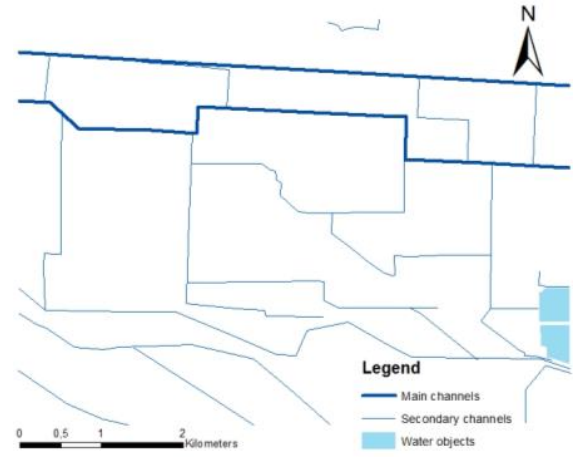

Fig. 1. Created water sets and object map for desert area (source Akmalov).



Fig. 2. Created water sets and object map for river area (source Akmalov).

Observations showed that the desert area consists of two water objects (lakes) and 19 irrigation sets. Only two of the investigated irrigation branches are more than 10 meters in width (main channels), the rest of the canals ' width is about 4-5 meters, and many other channels have a width of fewer than four meters. On the coastal area of the river, we have found four water objects, one of them a river, and it divides into 21 irrigation sets. Four branches out of those are 10 meters in width (Figures 1and 2).

\section{Results and Discussion}

During the eCognition analysis, the following indexes and layers were selected, and we have conducted an analysis of water objects:

$\mathrm{R} 1=$ Near infrared band of WV-2 satellite

$\mathrm{R} 2=$ Near infrared 2 bands of $\mathrm{WV}-2$ satellite

$\mathrm{R} 3=$ Panchromatic band of WV-2 satellite

R4=RedEdge band of WV-2 satellite

$\mathrm{R} 5=$ Brightness of $\mathrm{WV}-2$ satellite

$\mathrm{R} 6=\mathrm{NDWI}_{\mathrm{M}}=(\mathrm{G}-\mathrm{NIR} 1) /(\mathrm{G}+\mathrm{NIR} 1)$

$\mathrm{R} 7=\mathrm{NDWI}_{\mathrm{W}}=(\mathrm{C}-\mathrm{NIR} 2) /(\mathrm{C}+\mathrm{NIR} 2)$

$\mathrm{R} 8=\mathrm{NDWI}_{\mathrm{Ch}}=(\mathrm{G}-\mathrm{NIR} 2) /(\mathrm{G}+\mathrm{NIR} 2)$

$\mathrm{R} 9=\mathrm{NDWI}_{\mathrm{J} 1}=(\mathrm{C}-\mathrm{NIR} 1) /(\mathrm{C}+\mathrm{NIR} 1)$

$\mathrm{R} 10=\mathrm{NDWI}_{\mathrm{J} 2}=(\mathrm{B}-\mathrm{NIR} 1) /(\mathrm{B}+\mathrm{NIR} 1)$

$\mathrm{R} 11=\mathrm{NDWI}_{\mathrm{J} 3}=(\mathrm{B}-\mathrm{NIR} 2) /(\mathrm{B}+\mathrm{NIR} 2)$

$\mathrm{R} 12=\mathrm{NDVI}=(\mathrm{R}-\mathrm{NIR} 1) /(\mathrm{R}+\mathrm{NIR} 1)$

It did not bring any difficulty to separate water objects as they were big in all bands and indexes. In both images and all bands, water objects were fully identified. Prior attention was paid to identifying irrigation sets. The most difficult problem in identifying irrigation sets was the water shadow, but we could get rid of the small shades. We marked water 
objects with a small territory as the shade and classified them. The classification results are as follows:

Near-infrared band of WV-2 satellite. The smallest value of these bands gave us water objects. Due to this band, we could extract large water objects and big water branches. In both analyses, large water objects are fully determined. As Beshbulok village is located on the coastal area and as its main agricultural planting is rice growing, water full rice fields are also classified into water objects. That is why the map contains a lot of water objects.

The water objects in the region with a width of more than $10 \mathrm{~m}$ are completely determined. These irrigation branches are marked with thick lines and can be clearly seen. The unique issue in this band is its very sensibility. As a result, even the shades are marked as water objects. To prevent this problem and separate the shades from water objects, we have implemented the Pan band, Brightness, and Coastal band methods. However, it did not give positive results because of their sensibility. Only the smallest shades could be determined because of their small territory.

The advantages of WV-2 satellite are that it has a large spectrum, it has NIR 2 band, and it is considered much more sensible than NIR band. The low value of the present band gave us DN indicators of the smallest water objects. The irrigation lines in this band are clearer compared to NIR 1. The lines visually increased, became clearer. Therefore, the equal features of shade and water exist even here; thus, shade and water objects are mixed up [2426].

Panchromatic band of WV-2 satellite. The low values of this band demonstrate water objects; the panchromatic band also faces this problem. There are not only shade problems but also observed high sensibility of Pan band comparing to NIR. Of course, it is not difficult to identify big water objects through this band, but it has shortcomings in determination canals with a width between 10-20 m. The expected results in this band were very high. Because the resolution of this band equals $0.25 \mathrm{~m}$ pixel and it is predicted that it can determine small water objects with a width of less than $5 \mathrm{~m}$. But expectations failed. However, this band gave a little possibility of detecting small water objects than others (except NIR 2).

Red Edge band of WV-2 satellite. The conducted analysis by the Red Edge band is very close to the NIR1 band results because it is highly sensible like the NIR to large water objects and irrigations. The smallest values of this band composed pixel information of water objects as the previous. We can clearly see the big water objects' lines, but small water objects and their shades are messed up.

The brightness of WV-2 satellite. The analysis of brightness repeats the results of NIR 1. We marked its value as water objects and carried out the analysis.

If we conduct the analysis through the indexes, many indexes have been established for detecting water objects by many scientists. We have tested the most widely used ones in our analysis. However, the results are not as high as the band results. The scientists' work did not demonstrate positive results. The main reason for this is the vegetation covering irrigation objects [1]. For instance, it was impossible to determine small water objects with the help of the NDVI index. Usually, the smallest value of NDVI shows DN indicators of water objects. Therefore, it was impossible to identify small water objects, but also, some big water objects could not be detected. The reason for it is that sick vegetation increased the NDVI indicators [27-30].

The high value of the other indexes collected the pixel information of water objects. All the analysed results are lower than analyses extracting water objects through the NIR 2 band.

Only big water objects and irrigation branches were fully extracted through the $\mathrm{NDWI}_{\mathrm{M}}$ index analysis. $\mathrm{NDWI}_{\mathrm{J} 1}$ analysis showed the lowest result in extracting water objects by indexes in the Sirdarya region. Jawak's formulas rank lower according to its results. Our 
scientific prediction on this case is that Jawak carried out his analysis in the territory of Antarctica. These indexes are not suitable for arid areas. $\mathrm{NDWI}_{\mathrm{J} 2}, \mathrm{NDWI}_{\mathrm{J} 3}$ indexes gave a bit better results but were not so effective as NIR bands.

Thus, the most efficient band in extracting water objects regarding the analysis was the NIR 2 band. But in this analysis observed the joining the shade as others. Despite this, we could partly extract small water objects. If it is needed to extract large water objects from shades, it is recommended to implement NDVI NDWI $I_{11}$ indexes. However, it brings some difficulties in extracting middle-size water objects because of sick vegetation and cultivated lands. If one needs to take average accuracy level results, it is recommended to use the NDWIJ2 index. In this index, the shade mixed cases to water objects are less observed than other bands and indexes (except NDVI and $\mathrm{NDWI}_{\mathrm{J1}}$ ).

We made up a generalized table that includes all the results mentioned above. We can see the differences of analyses by this table (Table 3):

Table 3. Water extraction results (Source: Akmalov 2015)

\begin{tabular}{|c|c|c|c|}
\hline \multirow{2}{*}{ Objects } & Description of objects & Villages & $\begin{array}{c}\text { Total } \\
\text { number }\end{array}$ \\
\hline Water objects & $\begin{array}{c}\text { Lake, River, Seas, reservoirs, fish } \\
\text { farms, pounds }\end{array}$ & Beshbulak & 4 \\
\cline { 3 - 4 } & Yangiobod & 2 \\
\hline Main channels & $\begin{array}{c}\text { Irrigation sets in the region with } \\
\text { the width more than 10 m }\end{array}$ & Beshbulak & 4 \\
\cline { 3 - 4 } $\begin{array}{c}\text { Secondary } \\
\text { channels }\end{array}$ & $\begin{array}{c}\text { Irrigation sets in the region with } \\
\text { the width less than 10 m }\end{array}$ & Yangiobod & 2 \\
\cline { 3 - 4 } & \multicolumn{2}{|c}{ Beshbulak } & 21 \\
\hline
\end{tabular}

Table 4 continued

\begin{tabular}{|c|c|c|c|c|c|c|c|c|c|c|c|c|}
\hline \multirow{3}{*}{ Objects } & \multicolumn{12}{|c|}{ From total objects extracted objects by } \\
\hline & 㐒 & 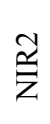 & $\underset{\Xi}{\tilde{\Xi}}$ & $\frac{1}{2}$ & $\dot{\varphi}$ & 爷 & 总 & 妾 & $\begin{array}{l}\vec{z} \\
\bar{z}\end{array}$ &  & 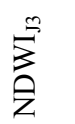 & 点 \\
\hline & 1 & 2 & 3 & 4 & 5 & 6 & 7 & 8 & 9 & 10 & 11 & 12 \\
\hline \multirow{2}{*}{$\begin{array}{c}\text { Water } \\
\text { objects }\end{array}$} & 4 & 4 & 4 & 4 & 4 & 4 & 4 & 4 & 4 & 4 & 4 & 4 \\
\hline & 2 & 2 & 2 & 2 & 2 & 2 & 2 & 2 & 2 & 2 & 2 & 2 \\
\hline \multirow{2}{*}{$\begin{array}{c}\text { Main } \\
\text { channels }\end{array}$} & 3 & 4 & 3 & 3 & 3 & 0 & 2.5 & 2 & 3 & 2 & 2 & 3.5 \\
\hline & 2 & 2 & 1.5 & 2 & 2 & 1 & 2 & 2 & 2 & 2 & 2 & 2 \\
\hline \multirow{2}{*}{$\begin{array}{l}\text { Secondary } \\
\text { channels }\end{array}$} & 15 & 18 & 9 & 7 & 11 & 0 & 1 & 4 & 7 & 3 & 3 & 5 \\
\hline & 15 & 15 & 13 & 10 & 11 & 1 & 11 & 5 & 0 & 7 & 10.5 & 9 \\
\hline
\end{tabular}

Small water objects are marked as straight lines, and they are not classified in our analysis. We calculated water branches according to long lines.

The conclusion was that NIR 2 band is the most efficient in determining water branches in Yangiobod and Beshbulak villages of the Sirdarya region. Investigations demonstrated that NIR 2 layer showed the highest accuracy. According to this formula, we could extract 32 water objects from the desert area and 36 water objects from the river area (Figures 3-4). 


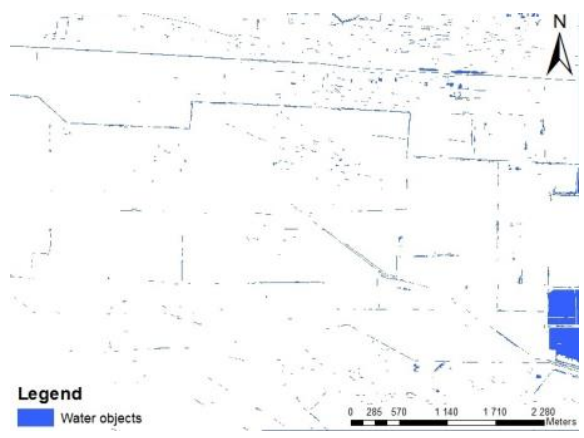

Fig. 3. NIR 2 Water extraction analysis result for Yangiobod village (Source WV-2 image of Yanigiobod village 12.09.2012)

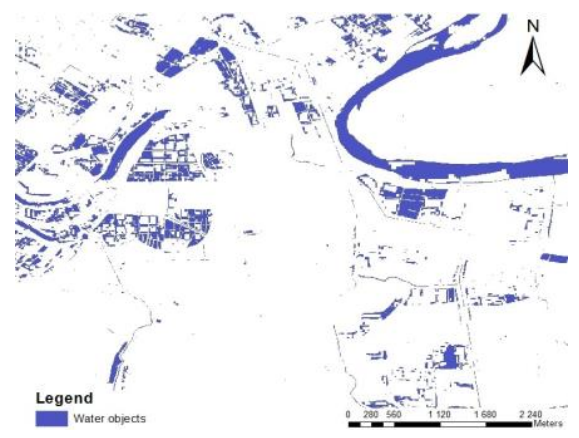

Fig. 4. NIR 2 Water extraction analysis result for Beshbulak village (Source WV-2 image of Beshbulak village 21.07.2011)

Regarding the NIR band, scientists of our Republic carried out many analyses concerning the identification of water branches, and they showed positive results. Our investigations one more time affirmed this. For example, Igor Klein recommends NIR band in extracting water by the middle-resolution images. He extracted large water objects of Central Asia by NIR band. The average accuracy indicators for MODIS images are $91 \%$. He had composed the map of surface water changes table during 27 years of scientific work [7].

Several more scientific investigations widely used in Uzbekistan's territory are McFeeters recommended formula of NDWI, and one of them is carried out by Bai and others. He observed the Aral Sea water surface during the last 30 years with the help of Landsat images. Here he used the NDWIM formula. The results were positive as expected. But it is very important to consider that the Aral Sea is a big water object, there is no vegetation in the drained parts of the Sea, and the content of soil and water has a big difference. We should work due to all the problems mentioned above in using HR images. However, our Landsat LU/LC analysis by NDWIM formula on the extraction of small water objects gave positive results, and so did the MIR band, too [9].

By the results of this analysis, we can recommend the optimal index for calculating water objects. The established new and rich map for water sets and resources is of benefit for the region.

We faced some difficulties in detecting small water objects in Beshbulak village. It was impossible to separate rice fields from water objects as they were filled with water Moreover, groundwater has also mixed with water objects as they come out the surface. This issue could be observed in Dubovyk's work. They classified water objects with the OBIA method and classified the waters mentioned above as agricultural lands. In conclusion, they marked those areas as flood areas [8].

In general, these territories are also full of water, and it is impossible to separate them. Only in one season, it is possible to separate them. This season is during the most developed period of rice; in this period, according to NDVI indexes of rice plants, it is possible to separate these areas from water. The second period is the harvesting period of rice. During this period, the water under the plants is dried especially. But due to our image was taken in the vegetation period and in this time rice fields will be under the water (see to compare to the crop rotation and development Table), we could not separate them.

\section{Acknowledgements}

The study was funded by Erasmus Mundus EACEA, Lille 1 University TVES laboratory, Tashkent institute of irrigation and agricultural mechanization engineers. 


\section{References}

1. Akmalov Sh.B., Gerts J., Samiev L.N. Using the Remote Sensing of Very high resolution images in observation of technical conditions of open drainage system in Syrdarya province. Science and world, 2013. P.136.

2. Alsubaie M.N. The potential of using WorldView-2 imagery for shallow water depth mapping. diss., 2012. University of Calgary. Web resource: http://theses.ucalgary.ca/handle/11023/353

3. Chen B.J.X., Li J., Yang L., Fang H. Changes in the area of inland lakes in arid regions of Central Asia during the past 30 years. Environmental monitoring and assessment, 2011. v.178. No 1-4. Pp. 247-56.

4. Baiocchi V., Brigante R., Dominici D., Radicioni F. Coastline detection using high resolution multispectral satellite images. In proceedings of FIG working week. 2012. Web

resource: https://scholar.google.com/scholar?cluster=556309128310902350\&hl=ru\&a s_sdt $=0,5$

5. Belgiu M., Drăguţ L., and Strobl J. Quantitative evaluation of variations in rule-based classifications of land cover in urban neighbourhoods using WorldView-2 imagery. ISPRS Journal of photogrammetry and remote sensing, 2014. V.87. P.205-15.

6. Chen Z., Ning X., and Zhang J. Urban land cover classification based on WorldView - 2 image data. in geomatics for integrated water resources management (GIWRM), 2012 international symposium on, 1-5. IEEE.

7. Dao P.D., and Liou Y. Object-based flood mapping and affected rice field estimation with Landsat 8 OLI and MODIS data. Remote sensing, 2015. V-7. No 5. Pp. 5077-97.

8. Dubovyk O., Menz G., Conrad Ch., Thonfeld F., and Khamzina A. Object-based identification of vegetation cover decline in irrigated Agro-Ecosystems in Uzbekistan. Quaternary International. Volume 311, 17 October 2013, Pp 163-174.

9. Gianinetto M., Rusmini M., Candiani G., Via G.D. Hierarchical classification of complex Landscape with VHR Pan-sharpened satellite data and OBIA techniques. European journal of Remote sensing, 2014. V. 47. Pp. 229-50.

10. Huang, X., Xie C., Fang X, and Zhang L. Combining Pixel-and Object-based machine learning for identification of water-body types from urban high-resolution remotesensing imagery. IEEE Journal of Selected topics in applied earth observations and remote sensing, 2015. V.8.No.5. Pp. 2097-2110.

11. Jawak, S. D., and Luis A. J. A Rapid Extraction of water body features from Antarctic coastal oasis using very high-resolution satellite remote sensing data. Aquatic Procedia, 2015. V. 4. Pp. 125-32.

12. Khin M.M.L., Shaker A., Joksimovic D., and Yan W.Y. The Use of WorldView-2 satellite imagery to model urban drainage system with low impact development (LID) techniques. Geocarto international, 2015. V. 31. No 1. P. 1-23.

13. Muratov, A., Melikuziev, S. Technology of formation of combined products of meliorative purpose (2020) IOP Conference Series: Materials Science and Engineering, 883 (1). DOI: 10.1088/1757-899X/883/1/012060

14. Maglione P., Parente C, and Vallario A. Coastline extraction using high resolution WorldView-2 satellite imagery. European journal of remote sensing, 2014.V. 47. Pp. 685-99.

15. McFeeters, S. K. The Use of the Normalized difference water index (NDWI) in the delineation of open water features. International journal of Remote sensing, 1996. V.17 (No 7). Pp. 1425-32.

16. Pengra B., Long J., Dahal D., Stehman S.V., and Loveland T.R. A Global reference database from very high resolution commercial satellite data and methodology for 
application to Landsat derived $30 \mathrm{~m}$ continuous field tree cover data. Remote sensing of environment, 2015. V.165. Pp. 234-248.

17. Vakhidova, U.A., Ibragimova, Z.I., Apakhodjaeva, T.U. Estimation of the temperature and humidity kinetics during the passage of vaporous moisture through textile materials (2020) IOP Conference Series: Earth and Environmental Science, 614 (1). DOI: $10.1088 / 1755-1315 / 614 / 1 / 012024$

18. Jurík, L., Zeleňáková, M., Kaletová, T., Arifjanov, A. Small water reservoirs: sources of water for irrigation (2019) Handbook of Environmental Chemistry, 69, pp. 115131. DOI: $10.1007 / 698 \_2018 \_301$

19. Ronczyk M., Wojtaszek-Levente M. Object-based classification of urban land cover extraction using high spatial resolution imagery. Remote Sensing of Environment. Volume 115, Issue 5, 15 May 2011, Pp. 1145-1161

20. Wolf A.F. Using WorldView-2 Vis-NIR multispectral imagery to support land mapping and feature extraction using normalized difference index ratios. in spie defense, security, and sensing, 2012. 83900N - 83900N. International Society for Optics and Photonics. Web resource:

21. Fatxulloyev, A., Allayorov, D., Otakhonov, M. Study of hydraulic parameters for concreting channels (2020) IOP Conference Series: Earth and Environmental Science, 614 (1). DOI: 10.1088/1755-1315/614/1/012054

22. $\mathrm{Xu} \mathrm{H}$. Modification of normalised difference water index (NDWI) to enhance open water features in remotely sensed imagery. International journal of remote sensing, 2006. V. 27 (No14). Pp. 3025-33.

23. Arifjanov A.M., Akmalov S.B., Samiev L.N. 2021. Extraction of urban construction development with using Landsat satellite images and geoinformation systems. Journal of Water and Land Development. No. 48 (I-III) p. 65-69. DOI 10.24425/jwld.2021.136147

24. Arifjanov, A., Samiev, L., Akmalov, S. Dependence of fractional structure of river sediments on chemical composition. (2019) International Journal of Innovative Technology and Exploring Engineering, 9 (1), pp. 2646-2649. DOI: 10.35940/ijitee.L2944.119119

25. Arifjanov, A., Apakhodjaeva, T., Akmalov, S. Calculation of losses for transpiration in water reservoirs with using new computer technologies. (2019) International Conference on Information Science and Communications Technologies: Applications, Trends and Opportunities, ICISCT 2019. DOI: 10.1109/ICISCT47635.2019.9011883

26. Arifjanov, A., Akmalov, S., Akhmedov, I., Atakulov, D. Evaluation of deformation procedure in waterbed of rivers. (2019) IOP Conference Series: Earth and Environmental Science, 403 (1). DOI: 10.1088/1755-1315/403/1/012155

27. Arifjanov, A., Samiev, L., Apakhodjaeva, T., Akmalov, S. Distribution of river sediment in channels. (2019) IOP Conference Series: Earth and Environmental Science, 403 (1). DOI: 10.1088/1755-1315/403/1/012153

28. Atakulov, D., Babajanov, F. Evaluation of the hydraulic and morfometric connections of the riverbed with using GIS (2020) IOP Conference Series: Materials Science and Engineering, 869 (4), DOI: 10.1088/1757-899X/869/4/042028

29. Abduraimova, D., Atakulov, D., Ibragimova, Z., Apakhodjaeva, T. Evaluation of erosion and accumulative process with using Geoinformation systems in water resource management (2019) International Conference on Information Science and Communications Technologies: Applications, Trends and Opportunities, ICISCT 2019. DOI: 10.1109/ICISCT47635.2019.9012020

30. Fatxulloyev, A., Abduraimova, D., Otakhonov, M., Atakulov, D., Samiev, L. Method designing of open drainages (2020) IOP Conference Series: Materials Science and Engineering, 883 (1). DOI: 10.1088/1757-899X/883/1/012047 